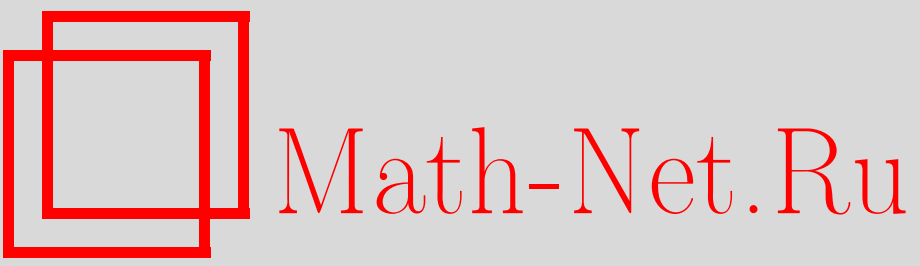

И. Ю. Ошева, В. Е. Шавшуков, Компьютерное моделирование сжатия образца из крупноячеистого пространственно армированного композита, заключенного в обойму для устранения влияния краевых эффектов, Вестн. Сам. гос. техн. ун-та. Сер. Физ.-мат. науки, 2011, выпуск 3(), 176-180

DOI: https://doi.org/10.14498/vsgtu943

Использование Общероссийского математического портала Math-Net.Ru подразумевает, что вы прочитали и согласны с пользовательским соглашением

http://www. mathnet.ru/rus/agreement

Параметры загрузки:

IP : 54.164 .48 .24

26 апреля 2023 г., $17: 24: 48$ 
УДК 539.411.4

\section{КОМПЬЮТЕРНОЕ МОДЕЛИРОВАНИЕ СЖАТИЯ ОБРАЗЦА ИЗ КРУПНОЯЧЕИСТОГО ПРОСТРАНСТВЕННО АРМИРОВАННОГО КОМПОЗИТА, ЗАКЛЮЧЁННОГО В ОБОЙМУ ДЛЯ УСТРАНЕНИЯ ВЛИЯНИЯ КРАЕВЫХ ЭФФЕКТОВ}

\section{И. Ю. Ошева, В.Е. Шавшуков}

Пермский национальный исследовательский политехнический университет, 614990, г. Пермь, Комсомольский пр-т, 29.

E-mails: irina-osheva@yandex.ru, shavshukov@pstu.ru

Работа посвящена численному моделированию эксперимента на сжатие призматического образиа из пространственно армированного композиционного материала, в котором ослаблень механизмы, приводящие $к$ смятию опорных поверхностей. Показано, что области максимальных напряжсний располагаются в рабочей части образиа, инициируя макроразрушение срезом. Для описания дебормирования и разрушения образца применяется структурно-феноменологический подxод.

Ключевые слова: пространственно армированные композичионные материаль, эксперимент на сжатие, структурно-феноменологический подход, численное моделирование.

Введение. K настоящему времени разработано достаточное количество методик проведения экспериментов для определения прочности при сжатии композиционных материалов, однако ни одна из них на сегодняшний день не является универсальной. Разработанные национальные (ГОCT, ASTM, DIN и др.) и международные (ISO) стандарты механических испытаний распространяются на полимерные композиты, армированные непрерывными борными, углеродными, органическими и др. волокнами, структура которых симметрична относительно их срединной плоскости. Для всех этих стандартов принимается допущение об однородности напряжённо-деформированного состояния (НДС) в рабочей части образца. Для этого необходимо, чтобы характерный размер структурных элементов композита (например, размер армирующей ячейки) был много меньше размеров рабочей части образца. Получившие в последнее время широкое распространение пространственно армированные композиционные материалы (ПАКМ) с крупноячеистыми волокнистыми каркасами и хрупкими минеральными поликристаллическими матрицами (углеродные, карбидные, оксидные и др.) [1-3] имеют размер армирующей ячейки $3-5$ миллиметров и более. Результаты испытания на сжатие образцов из таких материалов в значительной степени зависят от конструктивных особенностей приспособлений нагружающих машин и многих других параметров.

В работе [4] было исследовано влияние трения между плитами испытательной машины и образцом на напряжённо-деформированное состояние композитов с минеральной поликристаллической матрицей и трёхмерно-направленным ортогональным углеродным каркасом при сжатии (рис. 1). Показано, что для образцов с крупноячеистой структурой трение существенно снижает экспериментально измеряемые значения прочности. Проведённое параметрическое исследование влияния коэффициента трения позволило установить рост напряжений до $60 \%$ по сравнению с моделью эксперимента без учёта трения. Было выявлено, что области наибольших нап-

Ирина Юръевна Ошева, ст. преподаватель, каф. механики композиционных материалов и конструкций. Вячеслав Евгенъевич Шавшуков (к.ф.-м.н., доц.), доцент, каф. механики композиционных материалов и конструкций. 
ряжений для модели, учитывающей трение, располагаются не в рабочей части образца, а переходят на опорную поверхность, что ведет к инициации разрушения образца от смятия торцов, а не от среза в рабочей части, что считается характерным механизмом.

Для предотвращения смятия торцов образца можно применить несколько методов. Например, использовать специальные испытательные машины, обеспечивающие передачу нагружающих усилий на образец не только по опорной, но и по боковым поверхностям, или применить заливку торцевых поверхностей образца мягким сплавом, что сдерживает смятие материала образца около опорных поверхностей. Второй метод является более простым и дешевым в использовании, так как позволяет проводить испытания на прочность на стандартных испытательных машинах. При этом необходимо максимально снизить дополнительную концентрацию напряжений, которая может быть привнесена в эксперимент новыми конструктивными элементами. В данной работе осуществлено конечно-элементное моделирование эксперимента на сжатие призматического образца с целью выявления влияния заливки торцов на напряжённое состояние и прогнозирования вероятных механизмов разрушения материала в образце.

Схематичная модель данного эксперимента и модель образца представлены на рис. 1 и 2. Призматический образец, помещенный в мягкий сплав, ограниченный стальной обоймой в виде кольца, устанавливают на опорные плиты машины таким образом, чтобы его продольная ось совпадала с направлением действия нагрузки, а торцевые поверхности были параллельны опорным поверхностям плит. Испытательная машина снабжена двумя плоскопараллельными площадками (плитами), обеспечивающими сжатие образца с заданной постоянной скоростью.

Постановка краевой задачи. Краевая задача, соответствующая этому эксперименту, записывается в общем виде для анизотропных материалов и содержит:

- уравнения равновесия:

$$
\frac{\partial \sigma_{i j}}{\partial x_{j}}=0
$$

- геометрические соотношения Коши для случая малых деформаций:

$$
\varepsilon_{i j}(r)=\frac{1}{2}\left(\frac{\partial U_{i}(r)}{\partial x_{j}}+\frac{\partial U_{j}(r)}{\partial x_{i}}\right) ;
$$


- обобщённый закон Гука:

$$
\sigma_{i j}(r)=C_{i j m n}(r) \varepsilon_{m n}(r)
$$

где $\sigma_{i j}(r), \varepsilon_{i j}(r)$ - тензоры структурных напряжений и деформаций; $U_{i}(r)$ вектор структурных перемещений; $C_{i j m n}(r)$ - тензор структурных модулей упругости, $r$ - радиус-вектор с компонентами $\left(x_{1}, x_{2}, x_{3}\right)$.

Для экономии вычислительных ресурсов в силу симметрии модели образца для решения задачи была выделена $1 / 8$ часть образца, полученная разрезом координатными плоскостями.

Уравнения (1)-(3) дополняются граничными условиями: на всех точках опорной поверхности нагружающей плиты задано перемещение $U_{z}=U^{0}$; на контактирующих поверхностях образца, сплава и обоймы с поверхностью плиты задан закон сухого трения Кулона $\tau_{x z}=f \cdot \sigma_{z z}$ с коэффициентом трения $f$; между поверхностями нитей и матрицы, образца и сплава, сплава и обоймы задано условие идеального контакта:

$$
\sigma_{i j}^{(1)} n_{j}=\sigma_{i j}^{(2)} n_{j}, \quad U_{i}^{(1)}=U_{i}^{(2)} .
$$

На поверхностях разреза модели заданы следующие условия симметрии:

$$
U_{x}=0, \quad \tau_{x y}=0, \quad \tau_{x z}=0
$$

для плоскостей, перпендикулярных оси $O x$;

$$
U_{y}=0, \quad \tau_{y x}=0, \quad \tau_{y z}=0
$$

для плоскостей, перпендикулярных оси $O y$;

$$
U_{z}=0, \quad \tau_{z x}=0, \quad \tau_{z y}=0
$$

для плоскости образца, перпендикулярной оси $O z$; остальные поверхности модели являются свободными: $\sigma_{i j} n_{j}=0$.

Решение краевой задачи проводилось в рамках модели идеально хрупкого материала численно с использованием программного комплекса ANSYS 11.0, основанного на методе конечных элементов.

Численные результаты. Численные эксперименты показывают, что процесс разрушения образцов из исследуемых материалов начинается с повреждений в матрице. Разрушение армирующих нитей обычно происходит после появления достаточно обширных областей повреждения матрицы. Области повреждений матрицы на начальных этапах деформирования представляют собой локализованные области, дисперсно распределённые по объёму образца. По мере увеличения нагрузки эти области растут, появляются новые области и образуются кластеры повреждений матрицы, сравнимые по размерам с образцом. После этого образуется магистральная трещина, которая обычно проходит через эти кластеры. Решение упругой краевой задачи позволяет выявить области концентрации напряжений в матрице, которые вероятнее всего будут совпадать с областями повреждений в матрице. Поликристаллические матрицы являются гетерогенными средами с характерными размерами неоднородностей (кристаллитов) порядка десятков микрометров. В данной работе матрица рассматривается как однородная среда с эффективными свойствами. Поэтому все величины, относящиеся к матрице, в соответствии со структурно-феноменологическим подходом [5] должны рассматриваться как усреднённые по представительному объёму. Размеры представительного объёма для исследуемых матриц должны быть порядка нескольких сотен микрометров.

Представительные объёмы макроскопического уровня выбирались следующим образом: весь объём матрицы «разрезался» плоскостями, параллельными свободным поверхностям образца, на части определенной ширины и толщины, так, как 
это изображено на рис. 3. При этом ширина первых представленных объёмов $p_{1}$ и $q_{1}$ равна расстоянию от свободного края до нитей в направлении оси образца; вторых и третьих объёмов $p_{2}, q_{2}$ и $p_{3}, q_{3}-$ paдиусу нитей, а четвертых $-p_{4}$, $q_{4}$ - половине расстояния между нитями. Толщина (по оси $O z)$ представительных объёмов полагалась среднему значению ширины.

В качестве критерия разрушения матрицы был выбран критерий максимальных касательных напряжений, так как

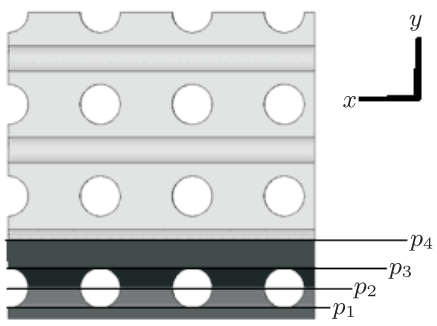

a

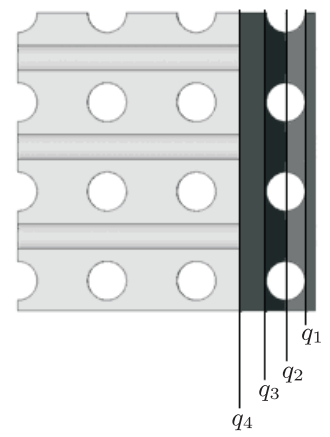

б

Рис. 3. Обозначение и расположение представительных объёмов (вид на опорную поверхность образца): a-p-объёмы; б-q-объёмы рассматриваемые матрицы обычно обладают низкими значениями прочности при сдвиге.

Как и в работе [4], было проведено параметрическое исследование зависимости напряжённо-деформированного состояния от коэффициента трения $f$, равного 0,3 и 0,6 .

Анализ результатов численного расчёта показал, что разрушение при сжатии образца из пространственно армированного композита, торцы которого залиты мягким сплавом, начинается с разрушения матрицы от сдвиговых напряжений в рабочей части образца в областях, расположенных вдоль плоскости под углом к опорной поверхности, а не от смятия на опорной поверхности.

Следует отметить незначительное влияние трения на прочность образца (не более $2 \%$ ). Кроме этого, для образца с залитыми мягким сплавом торцами отмечается существенное снижение уровня напряжений (около $40 \%$ ) по сравнению с моделью эксперимента без заливки торцов, но с учётом трения между опорной поверхностью испытательной машиной и поверхностью образца.

Заключение. Проведено компьютерное моделирование процесса сжатия образца из пространственно армированного композиционного материала крупноячеистой структуры для определения прочностных характеристик с учётом структуры материала. Рассмотрена модель эксперимента, в котором ослаблены механизмы, приводящие к смятию образца на опорных поверхностях. Численно показано, что области максимальных сдвиговых напряжений располагаются в рабочей части образца, инициируя макроразрушение срезом по плоскости. Такой механизм разрушения, как показывают эксперименты, приводит к бо́льшим значениям прочности при сжатии. Таким образом, следует ожидать, что при натурных испытаниях образцов из пространственно армированных композитов для определения прочностных характеристик более стабильные и более высокие значения могут быть получены на образцах, залитых мягким сплавом. При этом не нарушаются общие принципы обеспечения максимально возможной однородности напряжённо-деформированного состояния образца в рабочей зоне.

Работа выполнена при поддержке РФФИ (проект № 10-08-96062-р_урал_а) и ФЦП «Научные и научно-педагогические кадры инновационной России» (госконтракт 16.740.11.0508).

\section{БИБЛИОГРАФИЧЕСКИЙ СПИСОК}

1. Тарнопольский Ю.М., Жигун И.Г., Поляков В.А. пространственно армированные композиционные материалы. М.: Машиностроение, 1987. 224 с. [Tarnopolskiy Yu. M., Zhigun I. G., Polyakov V.A. Spatially Reinforced Composite Materials. Moscow: Mashinostroenie, 1987. 224 pp.] 
2. Соколкин Ю.В., Вотинов А. М., Ташкинов А.А., Постных А. М., Чекалкин А. А. Технология и проектирование углерод-углеродных композитов и конструкций. М.: Наука, Физматлит, 1996. 240 c. [Sokolkin Yu. V, Votinov A.M, Tashkinov A.A, Postnyh A.M., Chekalkin A. A. Technology and Design of Carbon-Carbon Composites and Constructions. Moscow: Nauka, Fizmatlit, 1996. 240 pp.]

3. Zweben Ed C., Tsai S.W. Comprehensive Composite Materials. Vol.4: Carbon/Carbon, Cement, and Ceramic Matrix Composites. Oxford: Elsevier Science Ltd, 2000. 622 pp.

4. Ошева И.Ю., Ташкинов А.А., Шавшуков В.Е. Краевые эффекты в крупноячеистых пространственно армированных телах в форме прямого параллелепипеда/ В сб.: $\mathrm{Me-}$ ханика микронеоднородных материалов и разрушение: Тез. докл. VI Всерос. конфции. Екатеринбург: ИМАШ УрО РАН, 2010. С. 80. [Osheva I. Yu., Tashkinov A.A., Shavshukov V.E. Edge effects for large cell spatially reinforced bodies in the form of a direct parallelepiped / In: Mehanika mikronyeodnorodnyh materialov i razrushenie. Ekaterinburg: IMASH UrO RAN, 2010. Pp. 80].

5. Соколкин Ю. В., Ташкинов А. А. Механика деформирования и разрушения структурнонеоднородных тел. М.: Наука, 1984. 115 c. [Sokolkin Yu. V., Tashkinov A. A. Deformation and Fracture Mechanics of Structurally Inhomogeneous Bodies. Moscow: Nauka, 1984. 115 pp.]

Поступила в редакцию 31/III/2011;

в окончательном варианте - 18/VIII/2011.

MSC: 74E30, 74A20

\section{COMPUTER MODELING OF COMPRESSION FOR LARGE CELL SPATIALLY REINFORCED COMPOSITE SPECIMEN ENCLOSED IN THE RING FOR ELIMINATION OF EDGE EFFECTS INFLUENCE}

\section{Yu. Osheva, V.E. Shashukov}

Perm State National Research Polytechnical University, 29, Komsomolsky pr-t, Perm, 614990, Russia.

E-mails: irina-osheva@yandex.ru, shavshukov@pstu.ru

Article is dedicated to numerical simulation of compression test of the prismatic specimen of the spatially reinforced composite material in which the mechanisms leading to collapse of basic surfaces are weakened. It is shown that areas of the maximum stresses settle down in a working part of the specimen, initiating macrodestruction by a cut. The structural-phenomenological approach is applied to the description of deformation and fracture of the specimen.

Key words: spatially reinforced composite materials, compression test, structuralphenomenological approach, numerical simulation.

Original article submitted 31/III/2011; revision submitted 18/VIII/2011.

Irina Yu. Osheva, Senior Teacher, Dept. of Mechanics of Composite Materials and Structures. Vyacheslav E. Shavshukov (Ph. D. (Phys. \& Math.)), Associate Professor, Dept. of Mechanics of Composite Materials and Structures. 